\title{
CONTRIBUIÇÕES DA LINGUÍSTICA APLICADA PARA O ENSINO DE PORTUGUÊS PARA SURDOS
}

\author{
Alzenira Aquino de Oliveira (UFS) \\ Mônica de Gois Silva Barbosa (UFS)
}

Resumo: A Linguística Aplicada (LA) no Brasil vem conquistando espaço e suas inúmeras ramificações demonstram que há uma série de possibilidades que se vislumbram em novos caminhos e novas práticas educativas, pois a LA está presente em todo processo de ensino e aprendizagem, inclusive no meio acadêmico. Assim, de acordo com o contexto educacional, social, político, cultural e identitário da comunidade surda que reivindica o ensino da Língua Portuguesa (LP) como segunda língua na modalidade escrita em todos os níveis educacionais, este estudo que se caracteriza como bibliográfico, tem relevância na medida em que proporciona uma abordagem com perspectivas inovadoras e transgressoras no que se refere ao ensino da LP como segunda língua. Diante desse contexto, o presente artigo tem como objetivo realizar uma reflexão acerca da prática de ensino da LP como segunda língua para surdos sob o viés de abordagem da LA. Para isso trilhamos inicialmente um caminho de reflexão sobre as concepções da LA, perpassando pela perspectiva de interculturalidade e considerando seu caráter transdisciplinar, tecemos uma breve discussão sobre a aplicabilidade da LA ao ensino de Português para pessoas surdas e abordamos algumas reflexões sobre a peculiaridade da produção escrita dos surdos. Para sua fundamentação, o presente estudo apoia-se em Moita Lopes (2009), (2016); Hooks (2013), Walsh (2009) e Brochado (2003). Com a análise aqui apresentada verifica-se a necessidade de mudanças na prática de ensino de LP para pessoas surdas.

Palavras-chave: Linguística Aplicada; Língua Portuguesa-L2; Escrita; Surdo.

Abstract: Applied Linguistics (LA) in Brazil has been gaining space and its numerous ramifications demonstrate that there are a number of possibilities that are envisaged in new educational paths and practices, since LA is present in the entire teaching and learning process, including in the academic environment. Thus, according to the educational, social, 
political, cultural and identity context of the deaf community that claims the teaching of the Portuguese Language (LP) as a second language in the written modality at all educational levels, this study, which is characterized as bibliographic, has relevance insofar as it provides an approach with innovative and transgressive perspectives regarding the teaching of LP as a second language. In this context, this article aims to reflect on the practice of teaching LP as a second language for the deaf under the LA approach. To do this, we initially followed a path of reflection on the concepts of LA, going through the perspective of interculturality and considering its transdisciplinary character. writing of the deaf. For its reasons, the present study is supported by Moita Lopes (2009), (2016); Hooks (2013), Walsh (2009) and Brochado (2003). With the analysis presented here, there is a need for changes in the practice of teaching LP to deaf people.

Keywords: Applied Linguistics; Portuguese Language-L2; Writing; Deaf.

\section{INTRODUÇÃO}

Há anos o ensino de língua portuguesa para surdos é concebido como objeto de estudo em diferentes áreas de investigação científica, como a Educação, a Linguística e a Linguística Aplicada, na maioria das vezes com o intuito de promover a melhoria do desempenho dos alunos surdos em práticas de leitura e escrita da Língua portuguesa (LP). Nosso interesse aqui é discutir, sob o foco da Linguística Aplicada, conforme defendido por Pennycook (1998, p.25) "tanto para criticar quanto transformar", as teorias apresentadas como referência, envolvendo o leitor numa reflexão que possibilite o reconhecimento das singularidades que envolvem o ensino da língua portuguesa para pessoas surdas. 
Dentre essas singularidades, destacaremos a peculiaridade pertencente à produção escrita do surdo. Sendo uma pessoa bilíngue, o surdo tem a Libras (Língua Brasileira de Sinais), como sua primeira língua (L1); isso vai interferir diretamente no aprendizado da Língua Portuguesa, sua segunda língua (L2). Essa interferência da língua de sinais na escrita do Português precisa ser considerada no processo de ensinoaprendizagem do surdo, pois é uma característica de aprendiz de segunda língua.

Nesse sentido, pretendemos contribuir com a construção de um ensino engajado com preocupações sociais, culturais e políticas que possibilitem o exercício da cidadania das pessoas surdas, enquanto pertencentes a um contexto de minorias. Por isso, este artigo trata de um assunto relevante, visto que permitirá ao leitor uma reflexão sobre o ensino de LP para surdos à luz da Linguística Aplicada LA, compreendendo melhor a particularidade linguística do surdo. Assim, o objetivo geral é refletir acera da prática de ensino da LP como segunda língua para surdos sob o viés da abordagem da LA.

Para discutir todas as questões acima levantadas, este estudo está sistematicamente desenvolvido obedecendo às seguintes etapas: será feito, primeiramente, um breve 
histórico da LA, em seguida, será feita uma reflexão do ensino de LP como L2 a partir da abordagem da LA, e, por fim, refletiremos sobre o ensino do português na modalidade escrita para surdos.

\section{LA - BREVE HISTÓRICO E CONCEPÇÕES}

A Linguística Aplicada é uma ciência recente que atualmente apresenta um campo de estudo transdisciplinar, porém sua gênese ocorreu nos anos 1940, nos Estados Unidos, tendo como interesse desenvolver materiais para o ensino de línguas durante a Segunda Guerra Mundial. Conforme aponta Moita Lopes (2009, p.13), somente em 1964 será constituída uma Associação Internacional (AILA), período em que ocorre o primeiro evento internacional de Linguística Aplicada. Este campo de investigação, relativamente novo, segundo Moita Lopes (2009, p.16) tem seus estudos, trabalhos e pesquisas iniciais enfocando a área de ensino-aprendizagem de línguas, na qual ainda hoje tem grande repercussão.

No Brasil, conforme citado, a LA começou por volta dos anos de 1980 com foco no ensino e aprendizagem de línguas estrangeiras e de forma semelhante ao que aconteceu no resto do mundo, estava atrelada à Linguística, na medida em que aplicava as teorias linguísticas ao ensino e aprendizagem 
de línguas. Confere-se inclusive à $L A$, desde essa época, a questão epistemológica da interdisciplinaridade e em meados dos anos 1990, a sua agenda começa a ser (re) definida, passando a reivindicar sua própria identidade e autonomia enquanto ciência. Em sua abordagem sobre a LA, Moita Lopes $(2009$, p.17) ressalta como sendo essa a fase da segunda virada, quando as áreas de pesquisa da LA começam a abranger contextos de ensino de língua materna, no campo dos letramentos e de outras disciplinas do currículo, e em outros contextos institucionais como a mídia, a empresa, a delegacia de polícia, a clínica médica, etc.

Conforme Menezes, Silva e Gomes (2009) há um consenso em torno da acepção do objeto de investigação da LA, é a linguagem como prática social, seja no contexto de aprendizagem de língua materna ou outra língua, seja em qualquer outro contexto onde surjam questões relevantes sobre o uso da linguagem. Assim, temos hoje a LA configurada como uma área imensamente produtiva, responsável pela emergência de uma série de novos campos de investigação transdisciplinar, de novas formas de pesquisa e de novos olhares sobre o que é ciência. (MENEZES; SILVA; GOMES, 2009, p.11).

Trabalhos realizados em LA contemplam temáticas que abordam desde o reconhecimento de problemas em que o 
uso da língua é o foco, até aqueles em que a interferência social do uso da linguagem em um meio específico é a discussão central. Nessa direção, Moita Lopes (2009, p.19) nos apresenta uma nova LA que emerge no início do século XXI, juntamente ao processo de ebulição nas Ciências Sociais e nas Humanidades, com as implicações da redescrição do sujeito social e seus desdobramentos epistemológicos cruciais. A tese defendida por esse autor é uma LA indisciplinar tanto no sentido de que reconhece a necessidade de não se constituir como disciplina, quanto em sua definição como uma área mestiça e nômade, que deseja ousar, pensar de forma diferente, para além de paradigmas consagrados, que se mostram inúteis e que precisam ser desaprendidos, enfatiza Moita Lopes (2009, p.19), citando Fabrício (2006).

Assim, encontramos uma LA que talvez seja mais bem entendida como transdisciplinar, no sentido de que deseja atravessar as fronteiras disciplinares, continuamente se transformando (MOITA LOPES, 2009, p.19), que perde o caráter solucionista que a acompanhou por muitos anos e que enfim abandona definitivamente sua preocupação em se limitar à Linguística como um componente teórico essencial, pois muitas das compreensões relevantes sobre a linguagem podem vir de outras áreas do conhecimento 
como a Geografia, Sociologia e Comunicação. Esse autor também afirma que este delineamento da LA não implica em prescindir de teorizações sobre linguagem, além disso, assegura que não há um cânone para a LA, ao contrário, ressalta que a perspectiva então é de indisciplinaridade em LA, o que requer um nível alto de teorização inter/ transdisciplinar, e por sua vez envolve leituras em diversos campos do conhecimento, participação de eventos em outras áreas e etc.

Sintetizando, Moita Lopes (2009, p.19) indica algumas características de uma LA indisciplinar, constituída por quatro aspectos igualmente relevantes, quais sejam: o caráter mestiço ou nômade desta ciência para dialogar com o mundo; a relação entre teoria e prática para as teorizações; a compreensão dos sujeitos sociais como históricos; e a existência de limites éticos para a ciência.

No panorama abrangente da LA a proposta é compreender o mundo contemporâneo e contribuir para uma agenda antihegemônica com pesquisas que alvitrem a desconstrução de posições que considerem inferioridade, submissão, subordinação, sujeição, dependência, desvantagem, subalternidade ou qualquer outra forma de domínio e supremacia; as vozes que são consideradas são as vozes 
dos sujeitos que vivem práticas sociais em que a linguagem apresenta papel central, sejam eles eleitores, falantes e/ou ouvintes em contexto de ensino-aprendizagem e fora dele; sujeitos heterogêneos, fragmentados e fluídos, são estes os sujeitos sociais considerados para a LA e o discurso desses sujeitos considerado como sendo a linguagem em prática social.

Nesse sentido, Rocha e Daher (2015, p.136) questionam como funciona a linguística aplicada e o que pode ela se tornar. Alerta-nos sobre as insuficiências do modo como a LA vem lidando com a dimensão social das práticas linguageiras e aponta como um desafio da LA a abordagem de uma concepção de social que não se defina nem em consonância com o modelo hegemônico das ciências exatas, nem a ele se oponha como seu contrário. Segundo os autores, não é suficiente caracterizar o trabalho da LA com ênfase no social, mas que é preciso adotar uma concepção de social. Argumentam também que não basta dizer que a LA é inter/ multidisciplinar, mas antes tem que se explicitar o lugar que ela dedicará ao não linguístico - que deve funcionar como efetivo intercessor na produção de um sentido de social que não guarde nenhuma relação com a ideia rasa de social que a modernidade produziu. 
As respostas para as indagações de como funciona a LA e o que ela pode se tornar, os autores deixam como reflexão e sugerem que um caminho seria eleger outros domínios do linguístico e do extralinguístico para fazer interseções e intercessões: e que possamos o mais brevemente possível inventar o sentido de social no qual desejamos investir e pelo qual entendemos que vale a pena lutar (ROCHA; DAHER, 2015, p.137).

Atingimos agora a concepção de que a LA não é uma ciência enclausurada que se obriga a desenvolver fórmulas e encontrar soluções corretas para o ensino e aprendizagem em um determinado contexto. A proposta da LA então é constituir-se como uma área investigativa inter/multi/ pluridisciplinar, com o objetivo de alcançar uma relação de equilíbrio e de produção de novos saberes através da colaboração de outras disciplinas, estabelecendo com elas laços sólidos.

Nesse contexto, elucidamos o ponto de vista de Alastair Pennycook (2006) sobre uma Linguística Aplicada Crítica (LAC) como uma abordagem mutável e dinâmica para as questões da linguagem e contextos múltiplos; compreendendo-a como uma forma de antidisciplina ou conhecimento transgressivo e como uma forma de pensar e 
fazer sempre problematizador. Isso quer dizer não somente que a LAC implica um modelo híbrido de pesquisa e práxis, mas também que gera algo que é muito mais dinâmico. 0 autor emprega a noção de transgressão para referir-se à necessidade categórica de utilizar instrumentos políticos e epistemológicos que permitam transgredir os limites do pensamento e da política tradicionais. A noção de teoria transgressiva por ele defendida visa marcar a intenção de transgredir, tanto política como teoricamente, os limites do pensamento e ação tradicionais.

A aplicabilidade de uma LA transgressiva que vai além dos limites normativos pode ser encontrada na prática desenvolvida em sala de aula por Hooks (2013, p.25) para quem transgredir é opor, resistir e cruzar os limites opressores da dominação pela raça, gênero e classe. Para Hooks, ensinar os alunos a transgredir tais fronteiras deve ser o objetivo primordial do professor cuja finalidade de sua prática seja atingir o dom da liberdade.

Diante das concepções sobre LA até aqui discutidas e das reflexões acima propostas, no contexto em que o mundo e as pessoas que nele habitam passam por mudanças substanciais, sendo constituídas por novas formas de existir e agir, finalizamos esta seção corroborando com Moita Lopes 
(2006, p.20) quando assinala que novos tempos exigem novas formas de teorizar.

\section{A LA E A LP COMO SEGUNDA LÍNGUA PARA SURDOS EM UM BRASIL PLURILÍNGUE}

Deparamo-nos atualmente no Brasil com a realidade de uma nação plurilíngue, de acordo com Oliveira (2008, p.03), são falados hoje em nosso país cerca de 210 idiomas. Constata o autor que as nações indígenas existentes no território brasileiro falam em torno de 170 línguas, as comunidades de descendentes de imigrantes outras 30 línguas, e as comunidades surdas do Brasil comunicam-se através de duas línguas de sinais, são elas a Língua Brasileira de Sinais e a Língua de Sinais Urubu-Kaapór. Apoiado em tais constatações, o autor evidencia então que somos um país de muitas línguas - plurilíngue - como a maioria dos países do mundo.

O mesmo autor ressalta que, da forma como a política linguística brasileira está estruturada nas universidades do país, os estudos da diversidade linguística, isto é, do plurilinguismo, ocupa apenas um modesto lugar nos esforços de pesquisa. De acordo com Oliveira (2008, p.07) quando se fala em diversidade linguística muitas vezes se pensa na diversidade interna da própria língua portuguesa. Mas como 
contraponto, o autor remete ao fato de que o interesse em pesquisas que incentivam a manutenção, difusão e desenvolvimento de diversas comunidades linguísticas, tem se revelado crescente.

Podemos afirmar que o fato de vivermos em uma nação plurilíngue paralelamente nos traz a constatação da existência da diversidade cultural, visto que habitamos no mesmo território geográfico com grupos culturais distintos. Esta realidade não é reservada ao Brasil, mas segundo Walsh (2009), desde os anos 1990, existe na América Latina uma nova atenção para a diversidade étnico-cultural e essa atenção surge da necessidade cada vez maior de promover ações positivas entre distintos grupos sociais, inclusive na parte jurídica, através de regulamentações que promovem o combate à discriminação, racismo e exclusão. Além disso, há uma preocupação com a formação de cidadãos conscientes da existência da diversidade e capazes de trabalhar conjuntamente para o desenvolvimento do país contribuindo com a construção de uma sociedade justa, equitativa, igualitária e plural. A autora destaca que a interculturalidade se inscreve nesta diligência.

Para Walsh (2009), é sob essa perspectiva que a interculturalidade crítica se entende como processo, projeto 
e estratégia que visa construir relações de saber, ser e poder partindo de realidades radicalmente distintas. Utilizando a categorização de Boaventura Sousa Santos, a autora ressalta que se trata de um projeto que questiona a sociologia das ausências. Por sua vez, Santos (2018, p.25) utiliza o termo sociologia das ausências metaforicamente para evidenciar que nas sociedades modernas há uma produção maciça de ausências: a nível de participação de grupos sociais (minorias) na produção de saberes e a nível de formas de vida social o que torna alguns indivíduos invisíveis e irrelevantes pois são classificados como ignorantes, primitivos, inferiores, locais ou improdutivos.

O maior grau de intensidade dessas ausências gera exclusões abissais. O sociólogo Boaventura de Sousa Santos (2018, p.32) na obra Epistemologias del Sur, postula e apresenta o conceito do pensamento abissal como uma característica da modernidade ocidental, a qual consiste num sistema de distinções visíveis e invisíveis que dividem a realidade social em dois universos ontologicamente diferentes. A linha invisível (abissal), que separa o mundo em países desenvolvidos (este lado), e subdesenvolvidos (o outro lado), evidencia as dominações econômicas, políticas e culturais, traduzidas por um lado pela hierarquização 
dos saberes e, por outro, pela negação da diversidade. No domínio do conhecimento, a ciência e o direito constituem as manifestações mais bem-sucedidas deste pensamento abissal na medida em que definiram, do ponto de vista científico, a distinção entre verdadeiro e falso e, do ponto de vista jurídico, a distinção entre legal e ilegal, impondo, internacionalmente, esta diferenciação através do direito internacional.

Para Santos (2018, p.33), superar o pensamento abissal é uma tarefa que exige o reconhecimento de sua persistência para que se possa pensar e agir para além dele em direção a um pensamento pós-abissal, que reflita partir do outro lado da linha, a partir de uma epistemologia do Sul e confrontando o monoculturalismo do Norte com uma ecologia de saberes. Nesse contexto a ciência moderna precisa estabelecer relação com outros conhecimentos e ter a consciência de que não é a única forma de conhecimento possível. Uma espécie de contra-epistemologia, que nega a existência de uma epistemologia geral e se baseia no reconhecimento de uma pluralidade de conhecimentos que se cruzam entre si. Ressalta o sociólogo que a expressão Epistemologias do Sul é uma metáfora do sofrimento, da exclusão e do silenciamento de povos e culturas que, ao longo da História, foram dominados pelo capitalismo e colonialismo. 
Seguindo este postulado nos deparamos com o cenário da comunidade surda, minoria que se encontra no outro lado da linha abissal e percebe-se que a linguagem gestual, utilizada como forma natural de comunicação, constitui-se em um vasto campo de estudos sob a égide da LA. Em seu escopo, a Linguística Aplicada permite contemplar o reconhecimento e uso da língua de sinais como foco de luta identitária da comunidade surda, perpassando pelas implicações de sociabilidade que tal diferença linguística impõe aos surdos no mundo, onde a maioria é ouvinte e utiliza a língua oral como principal forma de comunicação.

Encontramos então a Língua Brasileira de Sinais (Libras), língua minoritária utilizada como meio de comunicação da comunidade surda brasileira, reconhecida como língua recentemente, como conquista através do engajamento da minoria surda, configurando-se como campo de estudos da LA.

No início do século XXI com a Lei no. 10.436, de 24 de abril de 2002, que confere à Libras o status linguístico e em sequência, três anos depois, com o Decreto no 5.626, de 22 de dezembro de 2005 que regulamenta o uso, ensino e difusão da Libras, essa língua passou a ser alvo de pesquisas em diversas áreas do conhecimento, principalmente no 
campo do estudo de línguas, promovendo assim visibilidade aos aspectos formais das línguas sinalizadas. Posto isto, não há dúvida quanto à necessidade de recorrer-se a uma LA engajada e comprometida com as demandas sociais; uma LA indisciplinar como defende Pennycook (2006), traduzida como espaço dinâmico de investigação intelectual, para quem interdisciplinaridade tem a ver com movimento, fluidez e mudança.

É diante de tal contexto que trazemos à tona a questão do ensino da Libras como primeira língua da comunidade surda brasileira e a Língua Portuguesa assume o status linguístico de segunda língua dessa comunidade. Essa nova realidade linguística do surdo exige grandes mudanças e muitos desafios a serem enfrentados, especialmente por professores de LP na educação básica.

Por isso, inspirados em Bell Hooks (2013) propomos o desafio de transgredir as fronteiras linguísticas e, através de uma prática pedagógica transgressiva em sala de aula, cuja finalidade seja proporcionar aos alunos surdos a libertação e independência, resulte no engajamento e posicionamento frente à desmistificação da ideia de que os surdos não têm capacidade intelectual e não são aptos a desenvolver quaisquer tipos de atividades que envolvem a escrita e a 
leitura de uma língua oral, sejam elas educacionais ou não. Tais ideias equivocadas sobre os surdos geraram preconceitos que perduram até os dias atuais. Portanto, a LA entendida como inter/transdisciplinar contribuirá significativamente com o rompimento desse estigma para que os surdos tenham uma verdadeira inclusão na sociedade.

Diante disso, na seção seguinte faremos uma breve reflexão sobre o ensino de LP na modalidade escrita para surdos.

O ENSINO DE LP NA MODALIDADE ESCRITA PARA SURDOS

A educação inclusiva vem a cada dia assumindo um espaço central no debate acerca da sociedade contemporânea. O paradigma da inclusão defende o direito de todos os alunos estarem juntos, aprendendo em meio às diferenças. Entretanto, as marcas deixadas pela exclusão que perduraram durante séculos ainda estão presentes nas escolas.

Durante muito tempo os surdos não tiveram direito à educação, foram excluídos da sociedade e até privados de seus direitos legais. Em vários países da Europa, professores ouvintes desenvolveram métodos para ensinar aos surdos a língua de seu país. Alguns utilizaram o método “oralista puro", que se voltava unicamente para o ensino da língua falada. Outros acreditavam que a melhor metodologia 
de ensino para os surdos era o "método combinado", que utilizava a língua de sinais como meio para o ensino da fala (GOLDFELD, 2002).

Com o tempo foram surgindo pesquisas sobre línguas de sinais e, consequentemente, estudos sobre uma metodologia voltada para educação bilíngue que reconhece que a língua de sinais é a língua materna dos surdos e a língua oral é a segunda língua, no caso do Brasil, o Português na modalidade escrita.

Com a publicação do Decreto no. 5.626, de 22 de dezembro de 2005, que regulamenta a Lei no. 10.436, de 24 de abril de 2002, a Libras foi reconhecida oficialmente como língua: “É reconhecida como meio legal de comunicação e expressão a Língua Brasileira de Sinais (Libras) e outros recursos de expressão a ela associados" (Art.1우).

Essa mesma Lei, no seu artigo 13 afirma que:

O ensino da modalidade escrita da Língua Portuguesa, como segunda língua para pessoas surdas, deve ser incluído como disciplina curricular nos cursos de formação de professores para educação infantil e para os anos iniciais do ensino fundamental, de nível médio e superior, bem como nos cursos de licenciatura em Letras com habilitação em Língua Portuguesa.

De fato, faz-se necessário que professores tenham conhecimento da particularidade linguística da comunidade 
surda. É preciso também pensar em práticas de ensino que possibilitem aos surdos um ensino de LP que considere tais peculiaridades.

Diante disso, estudiosos como Quadros (2006); Salles (2004); Skliar (2009); Barbosa (2011), dentre outros, vêm refletindo sobre um ensino bilíngue para pessoas surdas. Outros pesquisadores ainda têm se dedicado ao estudo da produção escrita desses educandos, com destaque para Brochado (2003), Faria (2001), visto que tal produção apresenta marcas da interlíngua. Em suas pesquisas, os autores chamam a atenção para a interferência da Libras na escrita da LP por sujeitos surdos. Em tais estudos evidenciase que a Libras interfere diretamente na escrita da LP, visto que a articulação das características da Libras e da LP dá origem à interlíngua.

Esse termo interlíngua foi consagrado por Selinker, em 1972 (YOCATA, 2005). Assim sendo, interlíngua é uma denominação utilizada para designar a língua de um falante não nativo. Portanto, para a comunidade surda brasileira, refere-se a um texto cuja estrutura linguística combina a estrutura da Língua Portuguesa com a da Libras ou outras formas de sinalização.

Deste modo, a interlíngua é um processo natural que ocorre durante o processo de aprendizagem de línguas. 0 
aprendiz transfere as estruturas da sua língua materna para o aprendizado de uma segunda língua ou língua estrangeira. Sobre isso, Lado afirma que:

Sabemos, pela observação de muitos casos, que a estrutura gramatical da língua nativa tende a ser transferida para a língua estrangeira. $O$ aluno tende a transferir as formas das frases, os dispositivos de modificação, os padrões de números, gêneros e caso da sua língua nativa.

(1972, p.82)

Portanto, no processo de escolarização do surdo, a sua produção escrita estará sujeita a diferenciações. Por isso, nas fases iniciais, a sua escrita estará muito mais assinalada pelas características da Libras, enquanto nas fases finais desse processo, mesmo com particularidades, ela estará mais próxima do português, sua segunda língua (BARBOSA, 2011). Brochado (2003, p.308), demonstra esses estágios de interlíngua em sua pesquisa com crianças surdas.

De acordo com Brochado (2003, p.309), no estágio de interlíngua I, observa-se o emprego predominante de estratégias de transferência da língua de sinais (L1) para a escrita da LP (L2). No estágio de interlíngua II, verifica-se na escrita de alguns alunos uma grande combinação das duas línguas, enquanto que no terceiro estágio de interlíngua, há o emprego predominante da gramática da LP em todos os níveis. 
Desconhecendo essa realidade bilíngue dos sujeitos surdos, a escrita deles tem sido avaliada por professores como uma escrita "anormal e diferente", pois muitos educadores não compreendem a produção escrita desses alunos. Além disso, essa escrita é analisada como a primeira língua do surdo, e muitos educadores desconsideram as interferências da Libras ou de outras formas de sinalização ao avaliar tais construções textuais.

Assim sendo, diante dessa realidade linguística do surdo, e dos vários contextos em que a escrita se faz presente, urge repensar as práticas de ensino de LP para surdos e refletir de que maneira a escrita da LP-L2 se materializa nas produções.

Assim, possibilitar aos surdos o aprendizado de LP como L2 e considerar os estágios de interlíngua presentes em suas produções, permitirá ao surdo acessibilidade à informação e à comunicação em vários contextos sociais. Não apenas nas instituições de ensino, o surdo necessitará produzir textos escritos, mas, nos mais variados contextos. Sobre isso, afirma Viana:

$\mathrm{Na}$ sociedade atual, a escrita torna-se um instrumento insubstituível de acesso ao conhecimento científico, tecnológico e histórico, não só para os surdos, mas também para os ouvintes. A aquisição da escrita facilita o cotidiano das pessoas, permitindo 
que elas participem ativamente das mais diversas práticas sociais. $(2017$, p.67)

Como exemplo dessa prática social atual, pode-se ressaltar o uso crescente da escrita nas redes sociais, em que os surdos fazem uso diariamente através de mensagens enviadas por Twitter, Facebook, Blogs, Instagram, WhatsApp, entre outros, pois como afirmam Barbosa e Ferreira:

Vive-se em um mundo em rede, onde novos espaços de comunicação como as comunidades virtuais, blogs, fóruns e outros estão cada vez mais presentes, permitindo a interação social a partir do compartilhamento da informação, contribuindo assim para o surgimento de novas formas de aprender e de ensinar. (2013, p.83)

É diante desse contexto que Viana e Lima (2016) afirmam que os surdos têm percebido a importância do português escrito, nas trocas com ouvintes e até com os próprios surdos. As autoras ainda assinalam que:

Mesmo que a sociedade ouvinte conheça e reconheça que a língua de sinais possui regras gramaticais que asseguram a seus usuários acesso a conhecimentos e comunicação, poucos a usam. Nessa relação, encontramos uma situação bilíngue do surdo - em que a língua de sinais se constitui a L1, ou língua materna e natural, e o português escrito como L2, em que a escrita do português é significada, a partir da língua de sinais. (2016, p.12) 
Assim, faz-se necessária uma reflexão sobre a metodologia de LP para surdos, com o intuito de rever práticas ainda inadequadas, pois respeitar a particularidade linguística da pessoa surda e desenvolver um ensino de LP como metodologia de L2 concederá a comunidade surda um direito que lhe é garantido em Lei.

É imprescindível considerar também que o português é uma língua alfabética e os surdos não aprendem a escrever como os ouvintes, como ressaltado anteriormente, vários métodos já foram aplicados e ainda hoje persistem os problemas de alfabetização. As crianças surdas têm direito a uma educação bilingue, o que significa aprender a LP com metodologia de segunda língua.

\section{CONSIDERAÇÕES FINAIS}

A Linguística Aplicada tem muito a oferecer a todos aqueles pesquisadores que se interessam por auxiliar o homem a compreender melhor como ele constrói o seu conhecimento linguístico e, por conseguinte, como ele cria e expressa a sua identidade no mundo e nas suas relações sociais, através do uso da linguagem em todos os contextos.

Podemos afirmar que não há atividade humana na qual o linguista aplicado não tenha um papel a desempenhar. Por estarem diretamente empenhados na solução de problemas 
humanos que derivam dos vários usos da linguagem, os linguistas aplicados estão envolvidos em trabalhos que têm uma dimensão essencialmente dinâmica pois a LA considera que teoria e prática se imbricam na construção do conhecimento.

No que se refere à aplicabilidade das concepções da LA ao ensino da Língua Portuguesa, observamos que uma reorganização da disciplina $L P$, na escola que tem alunos surdos matriculados, é urgente. Não podemos mais seguir livros de alfabetização para ouvintes, principalmente com métodos fônicos. Precisamos, como Bell Hooks, transgredir, quebrar o tradicional e romper as barreiras, os alunos surdos necessitam de metodologias apropriadas para o ensino de segunda língua. Os alunos surdos têm o direito de se envolver em interações e comunicações significativas em sala de aula. As atividades devem seguir métodos de ensino de segunda língua e a escolha das técnicas a serem utilizadas carece de levar em conta uma abordagem comunicativa pela qual os alunos apreendam os significados e tenham insumos para expandir recursos linguísticos, com a oportunidade de observar a linguagem em uso.

Sendo assim, como citado na primeira parte desse trabalho, o panorama abrangente da LA, por sua vez pautada 
em concepções contra hegemônicas, é um dos caminhos que nos permite desconstruir a forma padrão de ensino da LP que no caso dos alunos surdos, com sua singularidade linguística, ficam em posição de submissão, inferioridade e desvantagem durante o processo de ensino e aprendizagem no contexto de uma sala e de uma escola onde a maioria é ouvinte, falante de uma língua que ocupa o status de supremacia na sociedade brasileira.

A pergunta que sempre se repete é: Porque é tão difícil alfabetizar crianças surdas? $E$ as respostas que temos é: Quem ensina o surdo? O que ensina o surdo? Como ensina o surdo? Talvez o primeiro passo seja buscar o conhecimento de práticas exitosas de ensino-aprendizagem de Português como segunda língua para pessoas com surdez. Quiçá a verificação da aplicação de metodologias de cursos de Português para estrangeiros e suas trajetórias. Quem sabe aliar-se a uma proposta de reorganização da disciplina Português na escola com alunos surdos, adotar livros de Português como L2, repensar a avaliação e o formato das provas de Português nas escolas de educação básica ou até mesmo produzir uma coleção de livros de Português para surdos.

Entendemos que conhecimento e compreensão precedem produção; leitura precede escrita; compromisso precede 
atitude; atitude precede engajamento; engajamento precede mudança; mudanças precedem novos tempos; novos tempos precedem novas formas de teorizar e novas teorias precedem novas práticas. Sem querer encontrar fórmulas mágicas, mas com vontade e compromisso de pensar com criticidade contínua a prática pedagógica do ensino e LP para surdos. E, sobretudo com alicerce nos paradigmas da LA, podemos encontrar as estratégias pedagógicas necessárias para intervire alterar o panorama do processo de ensino e aprendizagem da LP pelas crianças surdas.

\section{REFERÊNCIAS}

BARBOSA, Monica de Gois Silva (2011). O mecanismo da coerência na produção escrita dos surdos. Foco no vestibular 2011 da UFS. Dissertação (Mestrado em Letras), Universidade Federal de Sergipe (UFS).

BRASIL. Presidência da República (2002). Lei no 10.436, de 24 de abril de 2002. Dispõe sobre a Língua Brasileira de Sinais-LIBRAS e dá outras providências. Brasília.

(2005) Presidência da República. Decreto no 5.626, de 22 de dezembro de 2005. Dispõe sobre a regulamentação da Lei $n^{\circ} 10.436$ e o Art. 18 da Lei $n^{\circ}$ 10.098, Brasília.

BROCHADO, Sônia Maria Dechandt (2003). A apropriação da escrita por crianças surdas usuárias da Língua Brasileira de Sinais. 439 f. (Tese - Doutorado em Letras). Área de concentração: Filologia e Linguística Portuguesa. Faculdade de Ciências e Letras de Assis.

FARIA, Sandra Patrícia de (2001). "Interface da Língua Brasileira de SinaisLIBRAS (variante falada pela comunidade surda de Brasília) com a Língua Portuguesa e suas implicações no ensino de Português, como segunda Língua, para surdos". Revista Pesquisa Linguística, Brasília: LIV/UNB, 6(2), iii-xii. 
GOLDFELD, Márcia (2002). A criança surda: Linguagem e cognição numa perspectiva sociointeracionista. 4.ed. São Paulo: Plexus Editora.

HOOKS, Bell (2013). Ensinando a transgredir: a Educação como prática de liberdade. Marcelo Brandão Cipolla (Trad.). São Paulo. Editora Martins Fontes, p.223-233.

MENEZES, Vera Lucia; SILVA, Maria Morena dos Santos e; GOMES, Iram Felipe Alvarenga e (2009). "Sessenta anos de Linguística Aplicada: de onde viemos e para onde vamos". In: PEREIRA, R. C.; ROCA, P. Linguística aplicada: um caminho com diferentes acessos. São Paulo: Contexto, p.2550.

MOITA LOPES, Luiz Paulo (2009). "Da aplicação de Linguística à Linguística Aplicada Indisciplinar". In: PEREIRA, R. C.; ROCA, P. (Orgs.). Linguística Aplicada: um caminho com diferentes acessos. São Paulo: Contexto, p.1124.

(Org.) (2006). Por uma linguística aplicada indisciplinar. São Paulo: Parábola.

OLIVEIRA, Gilvan Muller de (2008). Plurilinguismo no Brasil. Brasília: UNESCO/IPOL.

PENNYCOOK, Alastair (2006). "Uma linguística aplicada transgressiva". In: MOITA LOPES, L. P. Por uma Linguística Aplicada Indisciplinar. São Paulo: Parábola Editorial.

(1998). "A Linguística Aplicada dos anos 90: em defesa de uma abordagem crítica”. In: SIGNORINI, Inês; CAVALCANTI, Marilda C. (Orgs.). Linguística aplicada e transdisciplinaridade. Campinas: Mercado de Letras, p.23-49.

QUADROS, Ronice Muller de (1997). Educação de surdos: a aquisição da linguagem. Porto Alegre: Artmed.

; SCHMIEDT, Magali L. P. (2006). Ideias para ensinar português para alunos surdos. Brasília: MEC, SEESP.

LADO, Roberto (1972). Introdução à linguística aplicada. 2.ed. Vicente Pereira de Souza (Trad. e Notas). Petrópolis, RJ: Editora Vozes. 
ROCHA, Décio; DAHER, Del Carmen (2015). "Afinal, como funciona a Linguística Aplicada e o que pode ela se tornar?". DELTA, 31(1), 105-141. SALLES, Heloisa Maria Moreira Lima et al. (2004a). Ensino de Língua portuguesa para surdos: Caminhos para a prática pedagógica. vol.1. Brasília: MEC/SEESP.

(2004b). Ensino de Língua portuguesa para surdos: Caminhos para a prática pedagógica. Vol.2. Brasília: MEC/SEESP.

SANTOS, Boaventura de Sousa et al. (2018). Epistemologías del Sur Epistemologias do Sul. Ciudad Autónoma de Buenos Aires: CLACSO; Coimbra: Centro de Estudos Sociais - CES.

SKLIAR, Carlos (Org.) (2009). Atualidade da educação Bilíngue para surdos. Interfaces entre pedagogia e linguística. 3.ed. Porto Alegre: Editora Mediação.

VIANA, Manuela Maria Cyrino; LIMA, Veraluce Silva (2016). "A Escrita da Língua Portuguesa como segunda língua por surdos nas redes sociais". Revista de Letras, 1(35), Jan./Jun.

WALSH, Catherine (2009). "Interculturalidad crítica y educación intercultural". (Conferência apresentada no Seminário Interculturalidad y Educación Intercultural", Instituto Internacional de Integración del Convenio Andrés Bello, La Paz). In https://docs.google.com/document/d/ 1GLTsUp2CjT5zlj1v5PWtJtbU4PngWZ4H1UUkNc4LIdA/edit Acesso em 18 de jul. 2020.

Alzenira Aquino de Oliveira é Mestre em Letras, Doutoranda em Linguística; UFS - Campus Universitário Prof. José Aloísio de Campos - São Cristóvão (SE); Linguística, Letras e Artes / Área: Letras / Subárea: Ensino de Línguas: língua portuguesa e LIBRAS. CORREIA, C. M. C.; BARBOSA, M. G. S.; OLIVEIRA, A. A. Língua Portuguesa como segunda língua para surdos: procedimentos da coerência na reescrita do texto. http://dx.doi. org/10.12957/cadsem.2018.34151, v.31, p.140-177, 2018. Núcleo de Pesquisa Inclusão Escolar da Pessoa com Deficiência (NUPIEPED); Grupo de Pesquisa em Análise e Elaboração Materiais Didáticos para o Ensino de Línguas Estrangeiras e Adicionais (GEMADELE) 
Lattes: http://lattes.cnpq.br/5923903102053905.

Email: alzeaquino@yahoo.com.br.

ORCID iD: https://orcid.org/0000-0002-5703-3896.

Mônica de Gois Silva Barbosa é Mestre em Letras, UFS; Graduação. Ensino de Libras. Língua Portuguesa como segunda língua para surdos; Análise da produção escrita de surdos: a interferência da Língua Brasileira de Sinais, In Surdez, Deficiência Auditiva e Educação Inclusiva, Criação editora, 2013, p.139-155. Grupo de Estudos e Pesquisas Identidades e Alteridades: Desigualdades e Diferenças na Educação (GEPIADDE); Grupo de Estudo e Pesquisa em Alfabetização, Discurso e Aprendizagem (GEADAS) e Grupo de Pesquisa em Análise e Elaboração Materiais Didáticos para o Ensino de Línguas Estrangeiras e Adicionais (GEMADELE).

Lattes: http://lattes.cnpq.br/4053462411412764.

Email:monicagsb@yahoo.com.br

ORCID iD: https://orcid.org/0000-0003-1402-3708

Recebido em 21 de julho de 2020

Aprovado em 13 de agosto de 2020 